\title{
Behavior Change and Prognosis in Patients With Heart Failure \\ - Salt Reduction Guidance and Readiness for Heart Failure Treatment -
}

Hiromitsu Sekizuka, MD, PhD; Keisuke Kida, MD, PhD

I nsufficient salt intake and water restriction are the leading causes of hospital readmission because of an exacerbation of heart failure (HF). ${ }^{1}$ During the coronavirus disease 2019 epidemic, the number of HF patients with inadequate salt and fluid intake has reportedly increased. ${ }^{2}$ The Japanese Circulation Society recommends sodium restriction for all patients with $\mathrm{HF}^{3},{ }^{3}$ so it is important to raise awareness and impart knowledge on salt reduction to prevent both the onset and exacerbation of HF.

In this issue of the Journal, Nakajima et $\mathrm{al}^{4}$ provide a new perspective on the relationship between a behavior change model and the prognosis of HF patients receiving salt reduction guidance. The behavior change model is one of the health theories advocated by Prochaska et al.,5,

\begin{abstract}
Article p 1555
Assessment of an HF patient's behavioral change allows physicians to understand the patient's psychological state, and, in turn, provide a tailored and person-centered approach to the patient. In their study, ${ }^{4}$ the salt intake of the patients was not calculated, and only a one-time salt reduction guidance session lasting about $30 \mathrm{~min}$ during the hospitalization was performed. Thus, the authors cannot declare that receiving salt reduction instruction directly improved the patient's prognosis. However, HF patients who made a behavioral change likely had a more favorable prognosis. Eliciting behavioral change by patients involves
\end{abstract}

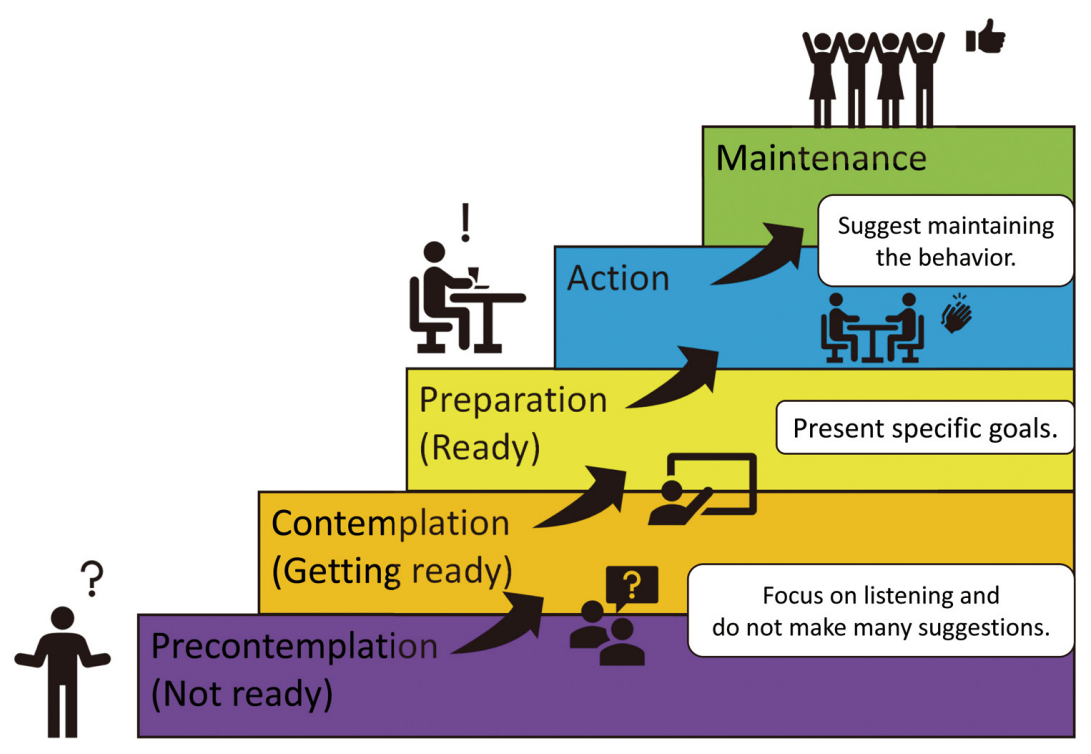

Figure. The transtheoretical model (TTM). In the behavioral transformation stage model, for a person to change a behavior, there are 5 stages to go through: "precontemplation" $\rightarrow$ "contemplation" $\rightarrow$ "preparation" $\rightarrow$ "action" $\rightarrow$ "maintenance". "Reversion" occurs when the behavioral change recedes.

The opinions expressed in this article are not necessarily those of the editors or of the Japanese Circulation Society.

Received May 31, 2021; accepted May 31, 2021; J-STAGE Advance Publication released online June 23, 2021

Department of Internal Medicine, FUJITSU Clinic, Kawasaki (H.S.); Department of Pharmacology, St. Marianna University School of Medicine, Kawasaki (K.K.), Japan

Mailing address: Hiromitsu Sekizuka, MD, PhD, Department of Internal Medicine, FUJITSU Clinic, 4-1-1 Kamikodanaka, Nakahara-ku, Kawasaki 211-8588, Japan. E-mail: sekizuka.h@jp.fujitsu.com

All rights are reserved to the Japanese Circulation Society. For permissions, please e-mail: cj@j-circ.or.jp ISSN-1346-9843 
a multidisciplinary approach and the results of this study support the importance of medical team care for patients with $\mathrm{HF}$.

\section{The Transtheoretical Model}

The behavior change model applied in the study is also called the transtheoretical model (TTM). According to this model, healthy behavior change progresses through 5 stages: indifference (precontemplation), interest period (contemplation), preparation period (preparation), execution period (action), and maintenance period (maintenance) (Figure). A patient trying to achieve good health is in one of these stages. A healthy behavior change requires different information at each stage, and intervention methods are designed according to the stage. Moreover, the model is not one-way, and a person undergoing behavioral transformation can enter the process at any stage, return to a previous stage, or start over. ${ }^{6}$ Aside from salt reduction guidance in HF patients, TTM has also been used in smoking cessation, alcohol restriction, weight control, and medication guidance. ${ }^{7,8}$

\section{Specific Approach to HF Patients Through Salt Reduction Guidance Using the TTM}

HF patients in the precontemplation stage are unwilling to embrace salt-reducing behavior for within 6 months. ${ }^{6}$ Typical statements include: "I do not feel the need for salt reduction."; "I am not sure how effective salt reduction is."; "I am unaware of the benefits of reducing salt and the burden of not doing so."; "I am not thinking of doing anything to reduce my salt."; and "I think that the burden of salt reduction is heavy." Therefore, it is crucial for patients at this stage to work on psychological and behavioral aspects: (A) considering the benefits of salt reduction in the treatment of HF; (B) obtaining knowledge and information on effective salt reduction and finding awareness of salt reduction and salt reduction behavior (raising awareness and emotional experience); (C) knowing that excess salt is the cause of exacerbation of HF and readmission; (D) being aware of the real reason why they cannot reduce salt and make excuses.

HF patients in the contemplation stage are not currently undertaking salt-reducing behavior, but they are willing to do so for 6 months. ${ }^{6}$ They feel hesitant or procrastinate in terms of the behavioral change. The following statements describe the feelings and perceptions of these patients: "I am interested in the benefits of reduced salt, but I am not ready to do it right away."; "I am not sure what to start with, and I am worried if I can do it."; and "I think it is better to stay as it is than to reduce salt." Therefore, it is crucial for patients at this stage to achieve the following: (A) deciding on specific actions to be taken; (B) reducing the burden of salt reduction and enhancing the benefits of salt reduction; (C) increasing awareness of salt reduction (raise awareness, emotional experience); (D) changing their self-image (reassessment of self and self-efficacy).

\section{Behavioral Change and Prognosis in HF Patients}

In this study, the prognosis of HF patients in the non-active states (precontemplation, contemplation, and preparation stages) was good. ${ }^{4}$ The differences in the backgrounds of HF patients need consideration. The health interventions in the health guidance improved the prognosis by increasing the TTM stage after the patients were discharged. Patients with a lower TTM level (non-active state) had better health consciousness after undergoing salt reduction and lifestyle guidance. In actual clinical practice, the effect of salt reduction guidance on sodium restriction is limited. The achievement rate of salt reduction guidance in patients with $\mathrm{HF}$ is approximately $25 \% .{ }^{9,10}$ However, even if $\mathrm{HF}$ patients do not reach their daily salt limit target, their prognosis can still improve with self-management and family support for salt reduction. ${ }^{11}$ Further studies on HF treatment and lifestyle modifications through salt reduction guidance, rather than imparting knowledge on salt reduction target values, are needed.

How the leader (healthcare worker) decides on the "goal setting" in collaboration with the target patient, and how much support is provided to achieve the goals, are the "keys" to success in behavioral change. When managing HF patients, it is important to render consistent medical team care in cooperation with multiple disciplines, such as doctors, nurses, pharmacists, nutritionists, and physiotherapists, according to the pathological condition and treatment of stage. ${ }^{3}$ Continuous care and guidance by the healthcare professionals improve the HF patient's motivation for treatment, leading to an improvement in prognosis. ${ }^{11}$

\section{Conflict of Interest}

The authors declare no conflicts of interest.

\section{References}

1. Tsuchihashi M, Tsutsui H, Kodama K, Kasagi F, Takeshita A. Clinical characteristics and prognosis of hospitalized patients with congestive heart failure: A study in Fukuoka, Japan. Jpn Circ J 2000; 64: 953-959.

2. Chagué F, Boulin M, Eicher JC, Bichat F, Saint Jalmes M, Cransac-Miet A, et al. Impact of lockdown on patients with congestive heart failure during the coronavirus disease 2019 pandemic. ESC Heart Fail 2020; 7: 4420-4423.

3. Tsutsui $\mathrm{H}$, Isobe $\mathrm{M}$, Ito $\mathrm{H}$, Ito $\mathrm{H}$, Okumura $\mathrm{K}$, Ono $\mathrm{M}$, et al; on behalf of the Japanese Circulation Society and the Japanese Heart Failure Society Joint Working Group. JCS 2017/JHFS 2017 guideline on diagnosis and treatment of acute and chronic heart failure: Digest version. Circ J 2019; 83: 2084-2184.

4. Nakajima T, Murata M, Nitta S, Shitara T, Kazama H, Satoh $\mathrm{Y}$, et al. Sodium restriction counseling reduces cardiac events in patients with heart failure. Circ $J 2021 ; 85$ : $1555-1562$.

5. Prochaska JO, Norcross JC, DiClemente CC. Changing for good, 3rd edn. New York: William Morrow, and Company, Inc., 1994.

6. Prochaska JO, Velicer WF. The transtheoretical model of health behavior change. Am J Health Promot 1997; 12: 38-48.

7. Suppan J. Using the transtheoretical approach to facilitate change in the heart failure population. Congest Heart Fail 2001; 7: $151-155$.

8. Paul S, Sneed NV. Strategies for behavior change in patients with heart failure. Am J Crit Care 2004; 13: 305-313.

9. Basuray A, Dolansky M, Josephson R, Sattar A, Grady EM, Vehovec A, et al. Dietary sodium adherence is poor in chronic heart failure patients. $J$ Card Fail 2015; 21: 323-329.

10. Lennie TA, Worrall-Carter L, Hammash M, Odom-Forren J, Roser LP, Smith CS, et al. Relationship of heart failure patients' knowledge, perceived barriers, and attitudes regarding low-sodium diet recommendations to adherence. Prog Cardiovasc Nurs 2008; 23: $6-11$.

11. Chung ML, Lennie TA, Mudd-Martin G, Moser DK. Adherence to a low-sodium diet in patients with heart failure is best when family members also follow the diet: A multicenter observational study. J Cardiovasc Nurs 2015; 30: 44-50. 